\title{
Incorporating Inequality Aversion in Health-Care Priority Setting
}

\author{
Joan Costa-Font ${ }^{1} \cdot$ Frank Cowell $^{2}$
}

Published online: 7 March 2019

(C) The Author(s) 2019

\begin{abstract}
Although measures of sensitivity to inequality are important in judging the welfare effects of health-care programmes, it is far from straightforward how to elicit them and apply them in health-care decision-making. This paper provides an overview of the literature on the measurement of inequality aversion, examines some of the features specific of the health domain that depart from the income domain, and discusses its implementation in health-system priority-setting decisions. We find evidence that individuals exhibit a preference for more equitable health distribution, but inequality aversion estimates from the literature are unclear. Unlike the incomeinequality literature, standard approaches in the health economics do not follow a 'veil-of-ignorance' approach and elicit mostly bivariate (income-related health) inequality aversion estimates. We suggest some ideas to reduce the disconnect between the income inequality and health economics literature.
\end{abstract}

Keywords Attitudes to inequality $\cdot$ Inequality aversion $\cdot$ Health $\cdot$ Income $\cdot$ Survey data $\cdot$ Priority setting

JEL Classification I19

\section{Introduction}

There is a widespread consensus that the attainment of health improvements is a desirable outcome of a health system. But there is more to health than the overall value of health-care treatment (Porter, 2010). For instance, new health technologies might improve the health of some individuals at the cost of increasing health

Joan Costa-Font

j.costa-font@1se.ac.uk

1 Department of Health Policy, London School of Economics and Political Science (LSE), Houghton Street, London WC2A 2AE, UK

2 Department of Economics, London School of Economics and Political Science (LSE), Houghton Street, London WC2A 2AE, UK 
inequality if other individuals cannot afford such new technologies, or are not aware of them and hence fail to use them. Accordingly, the reduction in health inequalities is recognised in legislation as one of the primary goals of European health systems. ${ }^{1}$ However, valuations of health-care programmes are seldom adjusted to allow for the welfare loss resulting from the health-inequality implications of different courses of action. So, an important question for the design and management of health systems is: how should one measure the extent to which a society is willing to trade off maximising health for reductions in health inequality? This is essentially what the economics literature defines as inequality aversion. A second question naturally follows: how should this measure of inequality aversion be incorporated in the prioritisation of health programmes?

Decisions on which health programmes should be financed entail trade-offs between heterogeneous notions of health-system value (such as health gain, health inequality and health-care quality), and in some cases between certain individuals who are lagging behind in some dimension of health status. When such a tradeoff exists, decision makers, as agents of a wider society, must implicitly or explicitly take account of how tolerant of inequality a society is. However, standard approaches to decision-making in health-care follow a utilitarian path by taking an unweighted summation of the health effects of a programme (Williams \& Cookson, 2000); only in exceptional circumstances is consideration given to the use of equity weights — one example of this is Robson, Asaria, Cookson, Tsuchiya, and Ali (2017). ${ }^{2}$ However, individuals' decision-making on social issues does not necessarily follow utilitarianism, in that individuals often favour options that are not the best outcome aggregated over all those affected (Baron, 1994).

Health is argued to be one of the basic freedoms and opportunities of individuals (Anand, 2002), a case can be made that only under very exceptional circumstances could one identify unambiguous instances of legitimate inequalities in health. By contrast, it is more common to identify income inequalities that are tolerated or justified on the basis of differences in effort (such as higher pay for longer hours of work), human capital investment (higher pay for experienced workers as opposed to workers undergoing training) or need (for example higher wages in more affluent provinces). In such circumstances, tolerance of inequality affects the welfare loss that a society experiences from living with health inequality, a decision maker ought to minimise the losses in people's wellbeing or utility. To do this, one needs to know the weight that society places on the health gains directed to those with poor health compared to overall health standards. However, to date we still lack clear evidence about how averse a society is to inequality in order to produce equity weights in guiding health-care priority setting, and whether such aversion is domain specific. ${ }^{3}$

\footnotetext{
1 See Costa-Font and Hernández-Quevedo (2012) for a summary of the application of such methods, and specifically to the measurement and use of bivariate (or income related) health inequalities.

2 Such weights can result from the use of a health-related social welfare function that increases with both an increase in aggregate health and a reduction of health inequalities (Culyer \& Wagstaff, 1993).

3 One of the limitations to elicit inequality aversion estimates lie sin that individuals tend to follow a "no harm' principle, namely that it is wrong to harm some people in order to help others, even though such a rule might lead to causing harm through omission (Baron, 1995).
} 
The view that inequality preferences vary by domain was developed by Tobin (1970) who coined the idea of 'specific egalitarianism' to distinguish a specific aversion to inequalities in 'basic needs', from inequalities in other (less basic) goods. ${ }^{4}$ However, this is ultimately an empirical question, especially in settings where information and knowledge are the most important: health-production inputs, which are, in turn, highly correlated with income (Kenkel, 1991).

In addition to the differences in attitudes across inequality domains, people's preferences might differ depending on what dimensions of the self, public or private are primed in the elicitation processes. That is, preferences may be contingent on the different roles people play in public and private realms: in the latter realm they are 'citizens'. Whilst individuals valuing health programmes as self-interested consumers of health care might not value a reduction in inequality in health, when they are asked about the issue as citizens who are making a choice in the abstract, they might give weight to equity considerations in making choices among healthcare programmes. ${ }^{5}$ In a health-system budget experiment revealing the valuation of health programmes relative to others, Costa-Font, Sato, and Rovira-Forns (2017) find evidence that individuals value health equity as one of the main goals of the health system in the context of a hypothetical health-care reform. This evidence is consistent with the idea that priority-setting decisions in the health sector result from some notion of 'fair share' in allocating resources (Margolis, 1984). ${ }^{6}$ Accordingly, individuals face a trade-off between allocating resources to the social group, and to themselves.

This paper attempts to provide answers to the following questions. How specific is inequality aversion in health, and how does it compare to other domains such as income? What are the methods available to elicit inequality aversion? How can information on inequality aversion guide the setting of priorities in the contexts of a publicly funded health insurance scheme? We begin with an overview of how to conceptualise inequality aversion in the health domain, and how it differs from the income domain. We discuss elicitation methodologies, and we also discuss the evidence from different studies, as well as how such evidence can be employed to inform priority setting in a welfare economic decision framework. We propose an inequality aversion elicitation strategy to emulate an environment of choice that is close to the 'veil of ignorance'. The idea behind the 'veil of ignorance' is that individuals should make choices blind to their own circumstances and self-interest. Finally, the paper proposes some notions to include inequality preferences in healthcare priority setting.

\footnotetext{
${ }^{4}$ However, such distinction is likely to vary on context specific value judgements. Basic needs in some countries might refer to food and first necessity goods, whilst in other settings, it might extend beyond those goods.

5 This might produce an allocation that would be closer to evaluations that would emerge from following a Harsanyi (1955) social welfare function.

6 According to Margolis (1984), for each person allocating individual and social resources, it is possible to identify a weight attached to resources allocated to the social group, and resources allocated to the individual.
} 


\section{Inequality Aversion in Health}

\section{Inequality Aversion: An Overview}

It is now well established that inequality aversion is an important parameter of an individual's welfare. Individuals usually prefer allocations between policy options that are perceived as 'fairer' than the alternatives, and experimental evidence shows participants are willing to face a sacrifice to act cooperatively (Fehr \& Gächter, 2000). Tricomi, Rangel, Camerer, and O'Doherty (2010) find neural evidence (changes in two areas of the brain, the ventral striatum and ventromedial prefrontal cortex) suggesting that high-pay individuals exhibit higher gain from paying to others as compared to themselves. In the context of attitudes towards the distribution of organ transplants, Ubel and Loewenstein (1996) find that individuals prefer an egalitarian equilibrium of giving everyone the chance of having a transplant even though the possibility of failure might be higher for certain groups, hence reducing overall health. This pattern of preference is clearly consistent with an approach that places positive weight on considerations of inequality aversion.

Amiel and Cowell $(1992 ; 1999)$ provided evidence of inequality aversion using questionnaire experiments and Cowell and Schokkaert (2001) explain how inequality aversion is reflective of risk preferences. However, there is still no consensus on the shape of such inequality preferences and its behavioural underpinnings, let alone the variability of inequality aversion parameters. Starmans, Sheskin, and Bloom (2017) argued that humans naturally favour fair distributions, not equal ones, and that when fairness and equality clash, people prefer 'fair inequality' over 'unfair equality'.

There is little consensus on the estimation of inequality aversion in the context of income; much the same applies in studies of attitudes to health inequalities. The approaches in the literature include the definition of the health-related welfare function and the incorporation of equity values in it (Wagstaff, Paci, \& Van Doorslaer, 1991), as well as the use of utility weights in the decision-making process (Robson et al., 2017). ${ }^{7}$

By contrast, in the sociology literature it is usually assumed that social norms determine what society regards as an 'acceptable inequality', and that such norms are shaped by common history and past institutions (Lübker, 2006). Some concerns on the elicitation of attitudes to inequality refer to the capacity of respondents to think carefully about a wellbeing sacrifice to attain an equity improvement. Inequality aversion can result from the process of social learning, by observing others' pay-offs (which may diminish the value of their own pay-offs). Hence, there have been limited efforts in the measurement of inequality preferences, especially in the health domain.

Health status may be only to a limited extent the result of individual choice: there is an important role for luck (Fleurbaey \& Schokkaert, 2011; Segall, 2010). If the luck component influencing health-for example, genetics-is perceived to be more important than in other areas of behaviour then that would lead to justifying different inequality preferences. Anand (2002) argues that we should be more concerned with inequalities in health than with inequalities in other dimensions as there is less that individuals

\footnotetext{
7 In the latter approach attitudes towards outcomes are separated from attitudes towards inequality but it does not capture the direct trade-off between outcomes and inequality in outcomes.
} 
can do to produce health. However, the extent to which this is true may be context specific: for example, it may be true for highly income-mobile societies, but not elsewhere. In this respect, Segall (2010) argues that health care is not a special domain in its application of luck egalitarianism.

The way an individual conceptualises the causality between health and choice can be explained by evolutionary expectations (Brosnan, 2006), or in terms of differential loss aversion. For example, Dolan and Robinson (2001) argue that loss aversion can explain differential inequality aversion in two experiments exhibiting different inequality aversion estimates. This is explained by the fact that reference points that people use can differ among individuals and vary across time; so, the final social equilibrium that determines inequality aversion might be affected by changes modifying such reference points. Envy can be a powerful factor underlying perception of loss. Alternatively, an individual's inequality aversion might reflect some larger 'group interest', which includes altruism but may extend beyond that to include identity-driven behaviour (Costa-Font \& Cowell, 2015).

\section{What is Special About Health-Inequality Comparisons?}

It is important to focus on the specific details of how people think about fairness in the health domain-for example, whether they think of health as the outcomes of choices, or whether the causality between choice and ill health is difficult to establish. Traditional concepts of inequality aversion focus on the distributions of equalisands such as income which that are both transferable and scarce (Bojer, 2005). In this respect, health is different from income as it is the outcome of a household production process and is produced subject to a higher level of uncertainty. Although some health inputs are known ex ante — such as health care — one can argue that health depends on a wider set of inputs such as nutrition and exercise, some of which are indeed transferable.

Most studies in the health domain estimate bivariate measures of inequality aversion which tend to use income (rather than health) as status variable to measure inequality and can be described as income-related health-inequality aversion (IRHIA). That is, these studies estimate the welfare reduction in health improvements among lowerincome (more deprived) groups. However, such measures are an extension of individual income-based inequality aversion measures to a different outcome variable (health rather than income) as opposed to health-inequality aversion. This is itself a significant departure from the elicitation methods of the income-inequality literature where inequality aversion refers to a single-variable equalisand, as we describe in the following section.

\section{A Simple Theoretical Framework}

Inequality aversion in the health domain requires an elicitation of individuals' trade-offs between changes in health and health inequality. This requires a theoretical framework that allows for a direct comparison of inequality aversion in different domains. An example of an inequality aversion framework applicable to different domains is the following model, developed by Carlsson, Daruvala, and Johansson-Stenman (2005). It is assumed 
that individuals care about their health or income $(y)$ and health or income inequality $(\Phi)$ according to preferences given by the following type of utility function

$$
u=h\left(y \Phi^{-\gamma}\right)
$$

where $\gamma$ is a parameter. For example, if we adopt the coefficient of variation as the inequality index $\Phi$, then (1) can be written as

$$
u=h\left(y\left(\frac{\bar{y}}{\sigma_{y}}\right)^{\gamma}\right)
$$

where $\bar{y}$ denotes average health status and $\sigma_{y}$ is the standard deviation of health status. Then take two different societies $A$ and $B$ that differ in how health is distributed, and identify the value of $\gamma$ that renders individuals indifferent between two societies that differ in their health status $y$ and health inequality $\Phi$ as follows:

$$
\gamma=\frac{\ln \left(y_{A} / y_{B}\right)}{\ln \left(\Phi_{A} / \Phi_{B}\right)}
$$

It is clear that the value of $\gamma$ will affect the welfare loss of alternative programmes that affect health and health inequality (or total income and income inequality). The rest of this paper will examine how to estimate and interpret such inequality aversion values.

\section{The Measurement of 'True' Inequality Preferences}

One of the main problems in measuring social decisions is that individuals are unlikely to reveal their 'true preferences', and will conceal their own self-interest. The Rawls (1971) concept of a 'veil of ignorance', behind which individuals seek to agree on appropriate social choice rules without knowing what position they will hold in society, is a convenient device for the purposes of discussion. However, the practical implementation of such a concept is limited given that individuals obviously do know their position in society. Whilst some studies try to emulate or approximate a veil of ignorance by posing hypothetical questions (or by asking individuals to consider decisions made on behalf of their descendants), other studies tend to disregard such veil-of-ignorance approaches and focus on eliciting people's values through choice or budget experiments.

\section{Choice-Based and Budget Experiment Methods}

A number of studies provide inequality-preference estimates by using methods involving choices between health programmes to test different elicitation procedures; some of these employ non-representative population sample data (Ali, Tsuchiya, Asaria, \& Cookson, 2017) whilst some work with samples that are representative of the general population (Abásolo \& Tsuchiya, 2008). Other studies employ online surveys to retrieve experimental evidence-for example Robson et al. (2017) use this method to elicit a measure of IRHIA for England. These studies produce inequality aversion estimates for policy purposes, but depart significantly from the standard methodology in the income-inequality literature, mainly because they define inequality as different 
health outcomes across groups defined by income levels as a measure of status. Furthermore, the participants' choices are made in the absence of a budget constraint to spell out the trade-offs implicit in the selection of alternatives with differing levels of inequality. Perhaps as a result of this, the inequality aversion estimates differ significantly in magnitude from those found in the income-inequality literature.

Abásolo and Tsuchiya (2013) elicit inequality aversion estimates from experiments involving subjects' choices of states of the world characterised by different amounts of inequality. Nonetheless, as with most studies in the health-economics literature, experimental evidence is typically not designed to conform to the theoretical requirement of veil-of-ignorance preferences. Furthermore, as is common in such empirical exercises, subjects are not presented with an implicit budget constraint in terms of the costs of alternative programmes that improve health equity.

Alternatively, other studies focus on choices of respondents acting as decision makers allocating a budget, which is what we can broadly define as 'budget experiments. Indeed, although some of the standard elicitation methods described above have an 'implicit budget constraint', they usually do not explicitly specify a budget constraint where the cost of a programme, either to the individual or the health system, is considered. An alternative option to elicit preferences over health-system equity lies in asking participants to allocate a budget resulting from a potentially realistic health-care reform to a number of health programmes attaining a number of health benefits. Costa-Font, Forns, and Sato (2015) report evidence from such a budget experiment to show that, although health-care programmes that improve health-care equity are highly prioritised, the willingness to allocate resources to such programmes (and hence to reduce the allocation to other programmes) is limited, suggesting that there is a limit to how much a society, even at a collective level, is willing to improve health-system equity. This is typically the case because prioritising programmes that improve health equity comes at a cost of expanding programmes that attain other healthsystem benefits. However, such kinds of study do not employ representative samples and, although they measure inequality aversion at a health-system level, they are not based on a veil-of-ignorance approach, such as those described in "Veil-of-Ignorance Approaches" section. So, it is likely that they are not reflective of individuals' 'true preferences'.

\section{Veil-of-Ignorance Approaches}

In contrast to elicitation techniques that directly elicit people's values, there are potential methods where people are not making choices purely based on their own immediate benefit. This is especially important in the health domain where the role of choice in explaining outcomes might be more restricted than in other domains. One recent approach consistent with the 'veil-of-ignorance' approach is Costa-Font and Cowell (2019) which employs the so-called grandchild approach to estimating individuals' aversion to both income and health inequality simultaneously. The paper uses the results from an internet questionnaire on income-inequality and health-inequality perceptions employing numerically based questions - see the accompanying text box for an example. By varying the magnitudes in the questions, it is possible to estimate the inequality aversion implied by the responses in both income and health domains. 


\section{Health Inequality Aversion}

Q1. Again we'd like to know what kind of world you would consider it better for your grandchild to live in. We ask you to make a choice between two scenarios A and B which differ in terms of the range of life expectancy in society (life expectancy is measured at birth; in every other respect A and B are the same) and let us know which, if any, you think would be better.

Scenario A Life expectancy is between 40 and 80, with an average of 60 .

Scenario B Life expectancy is between 60 and 70, with an average of 65 .

Keeping in mind your grandchild could be located anywhere in the range: Which scenario would you choose?
1. A
2. $B$
3. A and B equally good
4. Can't say

\section{Other Approaches}

The other approaches that have been employed by the general literature on inequality aversion are mostly specific to the case where income is used as the variable of interest. These include so-called leaky-bucket experiments, hypothetical trade union negotiations, dictator games and ultimatum games. However, all of them are hypothetical and involve pay-offs that are of limited use in health decision-making; this is principally because health, unlike income, cannot be transferred interpersonally.

\section{What Do We Know About Health-Inequality Aversion so Far?}

One of the most important finding from the literature is that the population exhibits widespread income-related health-inequality aversion, and that estimates of IRHIA are large, in most cases ten times larger than estimates for income-inequality aversion. However, such estimates derive from the use of heterogenous methods and techniques that vary considerably across studies. With very few exceptions, empirical studies in the health-economics literature are generally disconnected from the equivalent methods that are commonly used in the income-inequality literature. Although the methodological disconnect partly refers to the fact that income can be transferred, the use of veil-of-ignorance assumptions in eliciting inequality preferences is common to both literatures.

As mentioned, coefficients refer to income-related inequality aversion rather than to unconditional health inequalities. This means that attitudes towards other sources of health inequality are disregarded, and instead they reflect an extension of incomerelated inequalities to a different outcome variable. Whilst this approach is based on 
considerations that are relevant to policy in some western countries, it gives some indication of the scope of health inequalities.

Table 1 provides a list (by date of publication) of some of the principal studies that have attempted to estimate the trade-offs between health and a measure of health inequality, either within the population as a whole or within some naturally defined group, such as a city, or a role-defined group, such as politicians. The most salient feature is how heterogeneous the studies are. Some studies aim at finding equity weights to pursue a cost-effectiveness analysis in a way that accounts for population inequality aversion, whilst other studies either simply aim at testing for the presence of some attitudes that resemble inequality aversion, or test some of the underlying theories underpinning the potential social welfare function that explains people's preferences.

Early studies examine preferences of politicians as representatives of the population. Lindholm, Rosén, and Emmelin (1998) found that given a choice between two programmes (one which is more effective but does not eliminate inequality and the other which is less effective but eliminates inequality), Swedish politicians are prepared to sacrifice 15 out of 100 preventable deaths to achieve equity in death rates between blue and white-collar workers. Similarly, Emmelin, Lindholm, Stenlund, and Dahlgren (1999) estimate that $12.2 \%$ of respondents want to direct the programme towards the socially disadvantaged as opposed to improving the health of the general population. These results can be taken as evidence that actual decision makers care about health inequality. However, from this type of study one cannot conclude that the views of the population's representatives really represent the view of the population. This is the case because individuals' voting choices can be driven by a large number of disparate factors, and often health may not weigh heavily among those factors. Several other studies examine evidence from different samples of the general public. With a few exceptions these surveys are not representative of the population.

One of the important exceptions is Abásolo and Tsuchiya (2008) who survey a representative sample of the Spanish population to document evidence that the general public in Spain does have some concern about health equity. Furthermore, they identify some of the correlated factors about what makes some people more egalitarian than other, many of which — such as income or education-were not significant. Survey experiments have been used to examine the theoretical properties of people's choices on health equity (Abásolo \& Tsuchiya, 2013). Other important studies such as Tsuchiya and Dolan (2007) examine differences between member of the public and individuals working for the National Health Service, and they show that individuals are more averse to inequality than clinicians.

Abásolo and Tsuchiya (2014) examine survey evidence from Spain concerning decision makers who have to choose between two alternative health programmes. They specifically identify whether individuals that happen to be more altruistic are indeed more supportive of health-care programmes that are more equitable. Importantly, they confirm evidence of an association using blood donation as a proxy for altruism. On the underlying explanation for inequality aversion, Edlin, Tsuchiya, and Dolan (2012) find that, whilst responsibility matters, it does not seem to be pivotal in explaining people's choices that remained anchored in some level of 


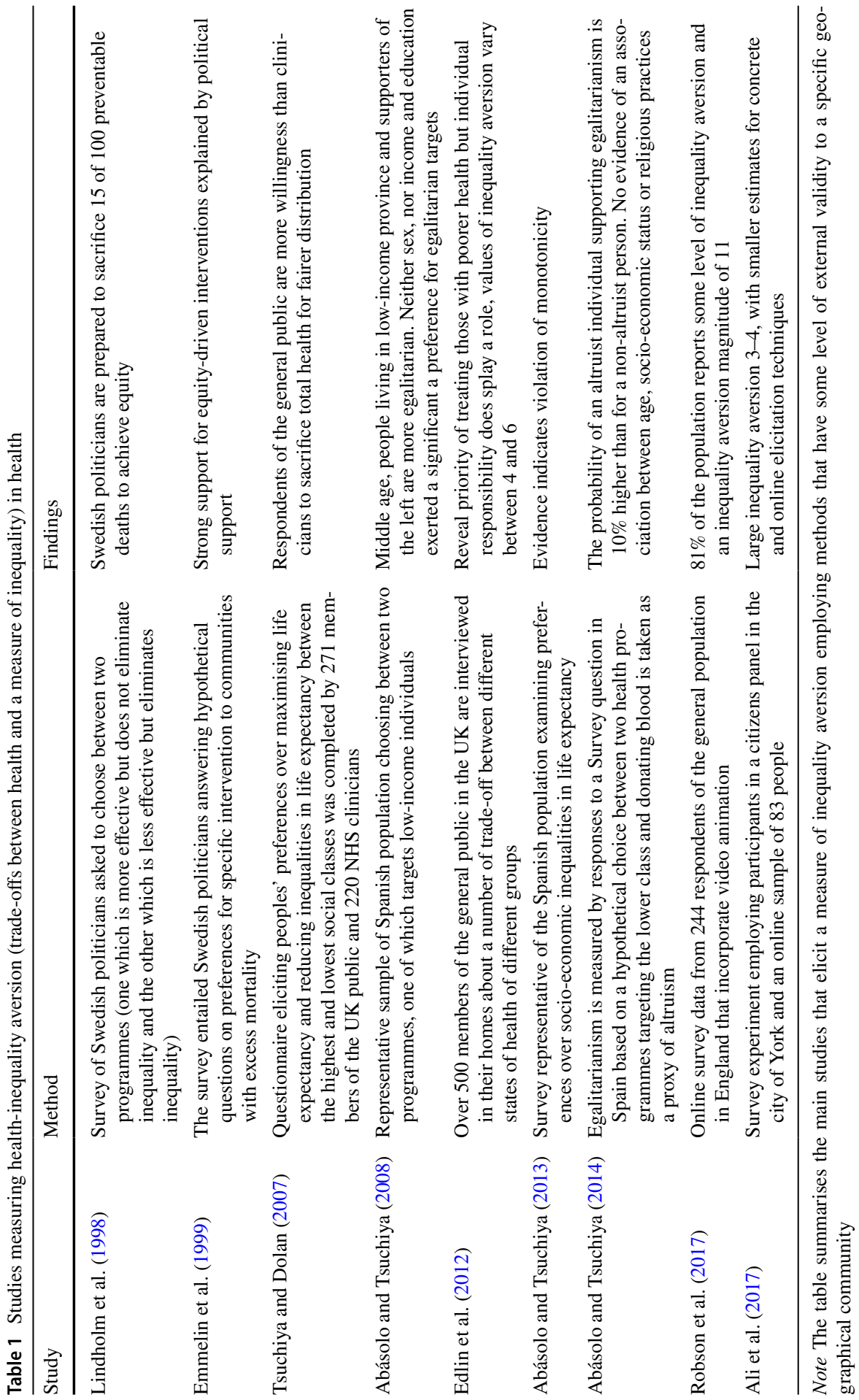


health-inequality aversion. Although employing a small-scale experiment, Dolan and Robinson (2001) invoke loss aversion as an explanation for differences in levels of inequality aversion across different experiments. This evidence suggests that there is a need to investigate further the behavioural foundations of health-inequality preferences.

Robson et al. (2017) employ pairwise choices between two programmes, which would increase expected years in full health and classify respondents as 'Pro-Rich', 'Health Maximisers', 'weighted Prioritarians' (give greater weight to the health of the worse-off), 'maximin' (improving the health of the worst-off) and 'egalitarians' (sacrifice potential health to benefit the worst-off). They find evidence that $81 \%$ of the population interviewed does exhibit inequality concerns of some kind, and they provide evidence of large implicit inequality aversion estimates. The data come from a small online survey that is not representative of the UK population.

Finally, Ali et al. (2017) use non-representative samples to provide estimates of the effect of elicitation techniques and modes of administration. They find evidence that inequality-reduction scenarios (whether large or small) did not make a difference but they find that concrete scenarios as opposed to abstract ones reduce inequality aversion, and that face-to-face surveys elicit higher inequality aversion; the latter finding is consistent with observability effects typical of decisions affected by warm glow.

\section{Inequality Preferences to Assist Priority Setting}

Given that individuals seem to be inequality averse, how should we best incorporate inequality aversion in setting priorities among health-care programmes? The WHO regards equity as one of the criteria to evaluate health-system performance. However, empirical evidence indicates that individuals when making health-system decisions subject to limited health-care budgets are not always prepared to sacrifice other potential health-care programmes that improve other dimensions of healthsystem value to reduce inequalities in health (Costa-Font et al., 2015).

The theoretical framework underpinning priority setting in health care assumes the presence of some kind of 'health-related social welfare function' which is maximised, subject to institutional and resource constraints. Equity considerations can be introduced through a variety of welfare approaches. They can enter the utility function as a 'value parameter', or as a weight on the health and welfare that different health-care programmes bring. Another way to introduce equity is by implicitly or explicitly weighting certain diseases or patient groups which, if treated, would improve the equity of the system (Olsen, 1997).

Nonetheless, some studies in health economics argue for extra-welfarist approaches which subscribe to the idea that health is a capability that is beyond individuals' choice (Coast, 2009). Accordingly, health can be maximised on its own, irrespective of individual utility considerations. However, such approaches ignore both equity and process utility gains, where the latter refers to gains from programmes that improve the process of health-care delivery but not health outcomes. Similarly, the pure maximisation of health ignores the fact that the same health gains 
to different individuals with different endowments might not affect social welfare to the same degree. Finally, as we have discussed above, there might well be potential health-equity gains from a health system.

The standard decision framework at the health-system context is that of choice of a subset of health programmes for possible implementation when there is insufficient budget to fund all of the available potential programmes. In such a context, some kind of priority setting based on the welfare effects (such as cost-effectiveness) can consider the equity effects of different allocations. Under these circumstances, one would need to adjust or weight the overall welfare of each combination of programmes by the preferences over how such a combination of programmes affect the distribution of health and other health-system outcomes.

\section{Conclusion}

The consideration of inequality preferences is an important piece of information in guiding health-care decision-making. We have argued that inequality aversion measures can be used to construct weights on the individual outcomes of different health-care programmes in order to assist the priority-setting process of publicly funded health systems. Higher aversion to inequality entails a higher weight on those health-care programmes that improve the health of individuals that exhibit poorer health. However, most of the existing techniques to assist health-care priority setting cannot properly consider the welfare effects of different distributions of health outcomes. So far, the literature in health economics has focused on preference-elicitation studies which typically elicit the trade-offs between different programmes affecting individuals of different socio-economic status. However, these studies show limited consensus on the value of inequality aversion estimates and, for the most part, exhibit limited external validity. That is, with few exceptions, most studies are experimental and they depart from the welfare-economics literature in that they do not propose a choice scenario that conforms to some 'veil-of-ignorance' measure. There are important limitations in the use of inequality preferences such as the limited standardisation in the elicitation procedures and the different conception of health equity mostly based on bivariate measures of (socio-economic or incomerelated) inequality; all of this is important for policy purposes.

Adopting domain-specific inequality aversion seems to be a sensible approach to follow, although we still know little about how inequality aversion varies by domain. If individuals exhibit different degrees of inequality aversion in the health domain and in the income domain, then one would expect the valuation of programmes that have no bearing on the distribution of income not to be adjusted by the incomespecific inequality aversion. Similarly, if a health programme does not influence the health of the population directly but rather through an indirect income channel (for example, through the amounts of copayment), then income-inequality aversion should be employed to compute its welfare effects.

Finally, it is important to acknowledge that there is substantial scope for bringing together the insights from the income-inequality literature and the health-economics literature, to produce analytical tools and measures that are theoretically sound, 
irrespective of the domain of inequality being examined. Overall, it is central to note two potential developments that could assist in achieving such a goal. First, studies measuring health-inequality aversion should attempt to include veil-of-ignorance approaches. Second, studies should ideally focus on distinguishing income- and health-inequality aversion estimates as opposed to eliciting a combined (bivariate) measure that does not take account of the domain of inequality.

Open Access This article is distributed under the terms of the Creative Commons Attribution 4.0 International License (http://creativecommons.org/licenses/by/4.0/), which permits unrestricted use, distribution, and reproduction in any medium, provided you give appropriate credit to the original author(s) and the source, provide a link to the Creative Commons license, and indicate if changes were made. The Creative Commons Public Domain Dedication waiver (http://creativecommons.org/publicdomain/zero/1.0/) applies to the data made available in this article, unless otherwise stated.

\section{References}

Abásolo, I., \& Tsuchiya, A. (2008). Understanding preference for egalitarian policies in health: Are age and sex determinants? Applied Economics, 40(19), 2451-2461.

Abásolo, I., \& Tsuchiya, A. (2013). Is more health always better for society? Exploring public preferences that violate monotonicity. Theory and Decision, 74(4), 539-563.

Abásolo, I., \& Tsuchiya, A. (2014). Egalitarianism and altruism in health: Some evidence of their relationship. International Journal for Equity in Health, 13(1), 13.

Ali, S., Tsuchiya, A., Asaria, M., \& Cookson, R. (2017). How robust are value judgments of health inequality aversion? Testing for framing and cognitive effects. Medical Decision Making, 37(6), 635-646.

Amiel, Y., \& Cowell, F. A. (1992). Measurement of income inequality: Experimental test by questionnaire. Journal of Public Economics, 47(1), 3-26.

Amiel, Y., \& Cowell, F. A. (1999). Thinking about inequality: Personal judgment and income distributions. Cambridge: Cambridge University Press.

Anand, S. (2002). The concern for equity in health. Journal of Epidemiology and Community Health, 56(7), 485-487.

Baron, J. (1994). Nonconsequentialist decisions (with commentary and reply). Behavioral and Brain Sciences, 17, 1-42.

Baron, J. (1995). Blind justice: Fairness to groups and the do-no-harm principle. Journal of Behavioral Decision Making, 8(2), 71-83.

Bojer, H. (2005). Distributional justice: Theory and measurement. Abingdon on Thames: Routledge.

Brosnan, S. F. (2006). Nonhuman species' reactions to inequity and their implications for fairness. Social Justice Research, 19(2), 153-185.

Carlsson, F., Daruvala, D., \& Johansson-Stenman, O. (2005). Are people inequality-averse, or just riskaverse? Economica, 72(287), 375-396.

Coast, J. (2009). Maximisation in extra-welfarism: A critique of the current position in health economics. Social Science and Medicine, 69(5), 786-792.

Costa-Font, J., \& Cowell, F. A. (2015). Social identity and redistributive preferences: A survey. Journal of Economic Surveys, 29(2), 357-374.

Costa-Font, J., \& Cowell, F. A. (2019). Inequality aversion: Effects of 'domain', 'inner attitudes' and 'personality'. London School of Economics, mimeo.

Costa-Font, J., Forns, J. R., \& Sato, A. (2015). Participatory health system priority setting: Evidence from a budget experiment. Social Science and Medicine, 146, 182-190.

Costa-Font, J., \& Hernández-Quevedo, C. (2012). Measuring inequalities in health: What do we know? What do we need to know? Health Policy, 106(2), 195-206.

Costa-Font, J., Sato, A., \& Rovira-Forns, J. (2017). Identifying health system value dimensions: More than health gain? Health Economics, Policy and Law, 12(3), 387-400. 
Cowell, F. A., \& Schokkaert, E. (2001). Risk perceptions and distributional judgments. European Economic Review, 45(4), 941-952.

Culyer, A. J., \& Wagstaff, A. (1993). Equity and equality in health and health care. Journal of Health Economics, 12(4), 431-457.

Dolan, P., \& Robinson, A. (2001). The measurement of preferences over the distribution of benefits: The importance of the reference point. European Economic Review, 45(9), 1697-1709.

Edlin, R., Tsuchiya, A., \& Dolan, P. (2012). Public preferences for responsibility versus public preferences for reducing inequalities. Health Economics, 21(12), 1416-1426.

Emmelin, M. A., Lindholm, L. A., Stenlund, H. C., \& Dahlgren, L. G. (1999). Pol-ethical considerations in public health: The views of Swedish health care politicians. The European Journal of Public Health, 9(2), 124-130.

Fehr, E., \& Gächter, S. (2000). Fairness and retaliation: The economics of reciprocity. Journal of Economic Perspectives, 14(3), 159-181.

Fleurbaey, M., \& Schokkaert, E. (2011). Equity in health and health care. In M. Pauly, T. McGuire, \& P. Barros (Eds.), Handbook of health economics (1st ed., Vol. 2, Chap. 16, pp. 1003-1092). Elsevier.

Harsanyi, J. C. (1955). Cardinal welfare, individualistic ethics, and interpersonal comparisons of utility. Journal of Political Economy, 63(4), 309-321.

Kenkel, D. S. (1991). Health behavior, health knowledge, and schooling. Journal of Political Economy, 99(2), 287-305.

Lindholm, L., Rosén, M., \& Emmelin, M. (1998). How many lives is equity worth? A proposal for equity adjusted years of life saved. Journal of Epidemiology and Community Health, 52(12), 808-811.

Lübker, M. (2006). Inequality and the demand for redistribution: Are the assumptions of the new growth theory valid? Socio-Economic Review, 5(1), 117-148.

Margolis, H. (1984). Selfishness, altruism, and rationality. Chicago, IL: University of Chicago Press.

Olsen, J. A. (1997). Theories of justice and their implications for priority setting in health care. Journal of Health Economics, 16(6), 625-639.

Porter, M. (2010). What is value in health care? New England Journal of Medicine, 363, 2477-2481.

Rawls, J. (1971). A theory of justice. Cambridge: Harvard University Press.

Robson, M., Asaria, M., Cookson, R., Tsuchiya, A., \& Ali, S. (2017). Eliciting the level of health inequality aversion in England. Health Economics, 26(10), 1328-1334.

Segall, S. (2010). Is health (really) special? Health policy between Rawlsian and luck egalitarian justice. Journal of Applied Philosophy, 27(4), 344-358.

Starmans, C., Sheskin, M., \& Bloom, P. (2017). Why people prefer unequal societies. Nature Human Behaviour, 1(4), 0082.

Tobin, J. (1970). On limiting the domain of inequality. The Journal of Law and Economics, 13(2), 263-277.

Tricomi, E., Rangel, A., Camerer, C. F., \& O’Doherty, J. P. (2010). Neural evidence for inequality-averse social preferences. Nature, 463(7284), 1089.

Tsuchiya, A., \& Dolan, P. (2007). Do NHS clinicians and members of the public share the same views about reducing inequalities in health? Social Science and Medicine, 64(12), 2499-2503.

Ubel, P. A., \& Loewenstein, G. (1996). Distributing scarce livers: the moral reasoning of the general public. Social Science and Medicine, 42(7), 1049-1055.

Wagstaff, A., Paci, P., \& Van Doorslaer, E. (1991). On the measurement of inequalities in health. Social Science and Medicine, 33(5), 545-557.

Williams, A., \& Cookson, R. (2000). Equity in health. Handbook of Health Economics, 1, 1863-1910.

Publisher's Note Springer Nature remains neutral with regard to jurisdictional claims in published maps and institutional affiliations. 